\title{
Enhancing Collaborative Learning Through Pedagogical Alignment
}

\author{
Júlia Justino and Silviano Rafael ${ }^{(\bowtie)}$ \\ Instituto Politécnico de Setúbal, Escola Superior de Tecnologia de Setúbal, \\ Setúbal, Portugal \\ \{julia.justino,silviano.rafael\}@estsetubal.ips.pt
}

\begin{abstract}
This paper presents a study conducted on a mathematics' course unit where the learner-centred approach was implemented. The study follows a quantitative approach based on surveys, complemented by typical actions of qualitative approach. The pedagogical structure developed is based on the constructive alignment between the objectives, the learning activities and the assessment. A pedagogical strategy with emphasis on the application of the collaborative working group and a comparative study of the outcomes achieved over the academic years of 2017-18 and 2018-19, pointing out some relevant aspects experienced by students, are presented.
\end{abstract}

Keywords: Collaborative learning $\cdot$ Pedagogical strategy $\cdot$

Constructive alignment $\cdot$ Learner-centred approach $\cdot$ Active learning

\section{Introduction}

The use of collaborative learning in Portuguese tertiary education has increased in recent years for it is suitable for the students training into the real world of work, in particular the development of key competences needed by students for the modern economy (OECD 2018). However, the application of a pedagogical structure to help the teacher to establish the pedagogical technique to adopt is still not a standard procedure in Portuguese tertiary education.

This paper arises from a study conducted on a mathematics' course unit of a tertiary technological course taught in a Portuguese polytechnic institute where the collaborative working group, in addition to other active learning techniques, was the main generator of active learning space within the classroom environment where the learner-centred approach was applied. The pedagogical strategy chosen in the setting-up of this curricular unit, solidly based on the pedagogical alignment established, was amended according to the data obtained in the previous academic year 2017-18 and also to the initial survey results which allow to define the new students' profile. This amendment triggered a significant improvement on the outcomes produced by active learning implementation. 


\section{Research Methodology}

Two research methods were applied in this study: a quantitative method and a qualitative method (Shaffer and Serlin 2004; Tashakkori and Teddlie 1998). In the quantitative method, based on students' investigations and assessments, three different surveys were carried out during the term time: initial, intermediate and final. The qualitative method, based on the interpretative approach given by the teacher's personal observation in classes upon the students' behavioural attitude along the learning process, provided useful information about how the learning process was being conducted.

\section{Context of Application}

In Portuguese polytechnics a new type of short-cycle tertiary educational programme (2 years - 180 ECTS) was added to the range of its course offerings, called Curso Técnico Superior Profissional (CTeSP). This programme, suitable for students from vocational education, has a strong practical and technological component in order to quickly provide the skills needed for students to join the labour market. The pedagogical method adopted in the mathematics' course unit presented in this paper was the learnercentered approach, in order to aggregate it with the other technical course units of the CTeSP. The pedagogical structure was designed taking into account the learning outcomes, the learning activities and the evaluation activities, being merged with the constructive pedagogical alignment (Biggs 1996) in all teaching and learning activities, consistently connected with the established learning outcomes. So the learning outcomes were related to the contents or the topics, the available resources, the active pedagogical techniques to be applied in each case and also to the time and type of evaluation carried out, forming a matrix. The implementation of the constructive alignment matrix requires reflection and continuous adaptation by executing a set of tasks such as: conceiving the pedagogical alignment between the learning outcomes and the learning activities, developing the learning activities and its necessary resources, implementing the pedagogical strategy that has to be in line with the learning activities, whether in classroom context or outside, continuously analysing the quality of training, which includes training and summative assessments, and adapting what is necessary according to previous results. To briefly summarise, all this procedure is developed to ensure that the pedagogical alignment exists and is respected during term time, allowing the articulation between the contents, the objectives, the students' training needs and the pedagogical techniques to be applied (Livingstone 2014). The pedagogical strategy implemented in the mathematics' course unit made use of several active learning techniques applied in the classroom environment. Qualitative and quantitative assessments were carried out to students during the classes in order to assess the progress of the application of the pedagogical structure. The development of the students' behavioural attitude (individually and in team), the specific objectives for each class within the mathematical contents and the need to optimize the students' working time, always providing them the necessary learning activities, were analysed throughout the term time. In this context, the collaborative working group (Barkley et al. 2014; Burke 2011; Chiriac 2014; Gokhale 1995; Laal and Ghodsi 2012) was the most applied active learning technique. 


\section{Pedagogical Strategy and Dynamics}

The implementation of the pedagogical structure aforementioned within the learnercentred approach, undergoes continuous reflective interactions, allowing the correction of the learning paths during term time, the change of the contents' format, the adaptation of the learning techniques and the improvement of the learning activities. Despite the positive results obtained in the previous academic year (Justino and Rafael 2018), some aspects of the initial pedagogical alignment established were amended in order to improve the expected outcomes. In particular, a change in the order of the topics covered, the addition of one more assessment element, regarding the learning outcome considered more difficult by the students in the previous academic year, and the implementation of more pedagogical techniques. Thus, several pedagogical techniques were applied in the learning activities, being the collaborative working group the most applied one. In situations of failures regarding previous knowledge or concepts, a personalized Just-in-Time Teaching (Gavrin 2006) was the learning technique used. Some learning activities were based on the Problem-Based Learning (PBL) technique (Duch et al. 2001). Other learning activities were based on Jigsaw (Aronson and Patnoe 1997) and Gallery Walk (Chin et al. 2015). All these techniques form the pedagogical strategy established by the constructive alignment matrix applied in the mathematics' course unit.

\section{Implementation of the Collaborative Working Group}

In academic year of 2017-18, the course coordinator divided students by four teams of four members each, which remained the same in all course units. In the academic year of 2018-19 there were five teams of four or five members each. In the first class of mathematics' course unit an initial survey was carried out aimed to identify the students' study habits and the students' attitude in classroom.

Regarding the characterization of the differences in the profile between students of the academic year 2018-19 and those of the academic year 2017-18, there is an increase of $15 \%$ of students studying individually, by a total of $87 \%$ of students. Since greater interaction and team work had to be developed, including in study, the collaborative working group would contribute to bring the students closer in this context.

On students' study habits and preparation for evaluations, there is a reduction of $8 \%$ of students stated to often summarise the contents to study later and an increase of $10 \%$ of students that only prepare themselves in the run-up to the evaluation, since they have a good memory. This means that students were accustomed to achieve superficial learning. It can be noted that students memorized the contents by summaries, not showing another type of study mechanism leading to a deeper assimilation and consolidation of knowledge. Classroom observation reinforced that most students did not demonstrate ongoing study habits, either individually or in team. So the learning activity had to take into account the need to provide, based on the collaborative working group, moments of deep learning.

On students' attitude, there is a slight reduction on the ability to actively participate in classroom, with $87 \%$ of students stating to be passive. This passive attitude, from previous school years, is typical of a strongly teacher-centred education in which the 
participation of students in not encouraged. So the need for an active and participative attitude enhanced the need for applying collaborative group techniques as a mean of supporting effective learning.

In the mid-term an intermediate survey was conducted for assessing the implementation of the learning process applied. It can be noted a slight variation of $1 \%$ between the two academic years, with $82 \%$ of students welcoming the collaborative working group. The sharing of expertise, the mutual assistance in solving problems and the group dynamics were the most reported aspects pointed out in this survey. The most significant negative aspect, stated by $30 \%$ of the students in the academic year of $2017-$ 18 , was the difficulty in having a four hours activity within which $19 \%$ also stated that they would have liked more time for the activity. In the academic year of 2018-19 the most significant negative aspect, also stated by $30 \%$ of the students, was the limited amount of exercises performed before the training tests. This last information was useful to put more available exercises on the IT platform used by the curricular unit.

In short, the information given by surveys allowed to adapt the type and the form of the learning activities in order to work out students towards a more participative and collaborative work and a shared study. To that extent the method of evaluation implemented in the mathematics' course unit was defined following the constructive pedagogical alignment matrix which integrates the topics to be studied and the learning outcomes to be achieved, considering the depth of contents based on Bloom's taxonomy (Amer 2006). The students' assessment consisted in four training tests, one oral test, two summative tests and peer review, with students being encouraged to achieve $70 \%$ of the contents' skills on training tests. On the intermediate survey students pointed the method of evaluation as one of the major strengths of the learning process.

\section{Outcomes of the Implementation}

On the final survey, $78 \%$ of the students stated to have been encouraged to participate and discuss the topics over classes, representing a slight increase of $3 \%$ compared with the previous academic year. The remaining $22 \%$ stated not to always have an active and participative attitude during the learning activities. On collaborative work, $69 \%$ of the students stated to feel supported by the remaining team, facilitating their social integration through sharing of knowledge relating to the curricular unit, $25 \%$ stated that the support of the remaining team was not frequent and only $6 \%$ of the students showed social and interaction difficulties with the remaining team. On the working group dynamics, the mutual assistance during the learning activities was positively reported by $96 \%$ of the students that also considered the team to always have worked well, which stands for a significant increase of $27 \%$ compared with the previous academic year. This result satisfies the goal of greater student interaction with contents and knowledge sharing established in the pedagogical alignment matrix since only $4 \%$ of students considered that the team didn't work out so well. Also, on the group learning, $91 \%$ of the students stated to have learned more in team than individually, which stands for an increase of $10 \%$ compared with the previous academic year. 


\section{Outcomes of the Academic Performance}

\subsection{Group Performance}

In Fig. 1 below, the average ranking of the teams' performance is presented in a bar graph (with teams A, B, C, D and E) Teams from different academic years were associated by profile's similarity and leadership characteristics. It can be noted a relevant similar evaluation of the competences achieved according to the teams' profile. This relationship is undergoing a deeper study in the next academic years. Some of the teams' characteristics were analysed in order to join them as follows.

Team A is characterised by shared leadership, good cohesion and knowledge consistency, presenting a fast learning capacity. Both teams A had one of the best pupils of the class. The collaborative working group provided a high dynamic in knowledge sharing and more commitment to competence development.

Team B is characterised by lack of leadership, weak cohesion and interpersonal relations, diversified knowledge and communication difficulties, presenting a differentiated academic performance among its members. Both teams B lost a member who dropped out by the end of term time. The collaborative working group fostered the communication and team work skills.

Team $\mathrm{C}$ is characterised by strong leadership with passiveness of the remaining members, little cohesion, diversified knowledge and some communication skills. Despite the positive outcomes presented, the excessive passivity hampered a wider development of the desired competences.

Teams D and E are characterised by shared and communicative leadership. Although there was a profound lack of background knowledge among its members, good commitment, great sharing capacity and good interpersonal relations could be observed. The collaborative working enabled students to share knowledge and provide mutual assistance, handling the lack of background knowledge.

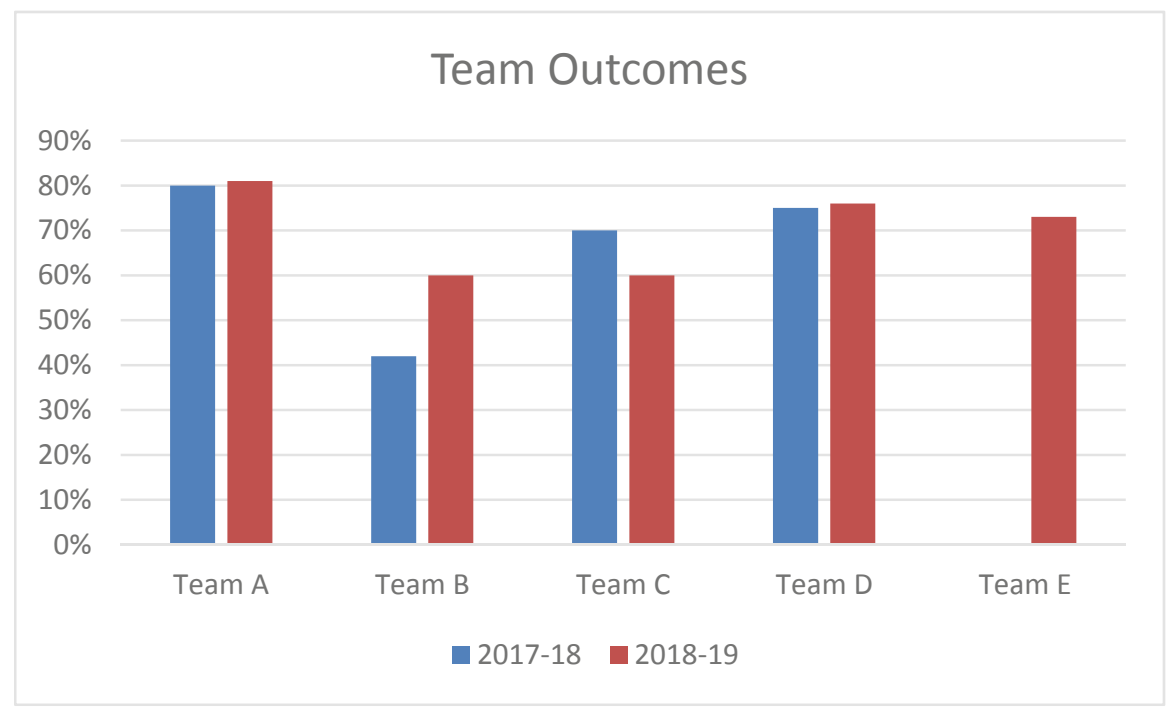

Fig. 1. Outcomes of the teams over the past academic year 
In short, the collaborative working group provided the exercise of knowledge sharing and the metacognition application, highlighted in teams D, E and A, being the booster of motivation and commitment in problem-solving in all teams. The passivity and the lack of communication and sharing among the team members are the main factors that produce inertia into the development of the desired competences.

\subsection{Individualized Performance}

In Fig. 2 below, the performance outcomes of each student are presented by team. Overall, the success rate has increased from $80 \%$ to $93 \%$ in the academic year of 2018 19. Although the average score in 2018-19 is not higher than in 2017-18, more students achieved a positive score.

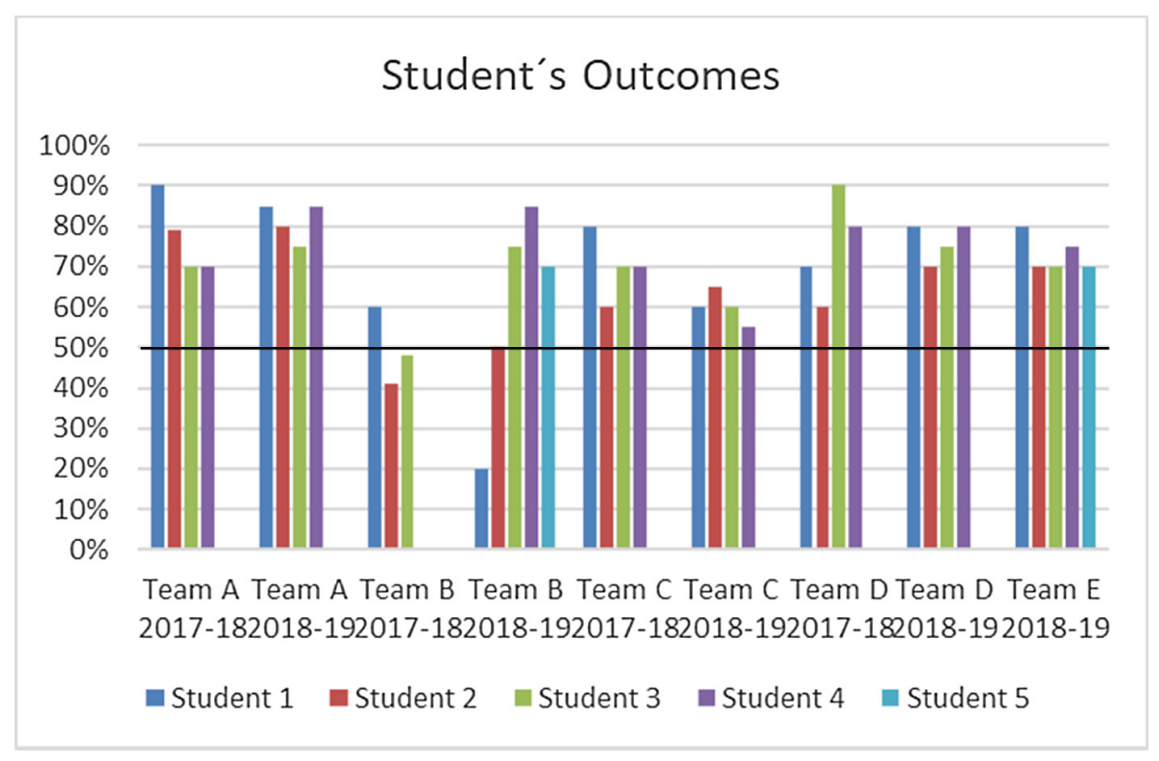

Fig. 2. Student's outcomes by team.

It should be noted that in the final survey carried out in $2018-19,78 \%$ of the students classified the learning process applied to mathematics' course unit as good or excellent and the remaining $22 \%$ as satisfactory. This represents an increase of $18 \%$ concerning the degree of satisfaction when compared with the academic year of 2017-18.

\section{Conclusions}

Since Mathematics is a cross-cutting scientific area whose contents, although necessary for student's training, hardly fit into projects of strong technological nature, the application of active learning techniques allows its articulation with the other technical 
course units of a CTeSP. This contributes for the development of the students' soft skills, such as team work, autonomy, organisation, critical thinking, among others. Also, the teacher-student relationship that is established is closer, respectful and clear which is an important motivation factor for the student's academic performance, contributing to reduce the drop-outs rate in the course unit.

The collaborative working group, Jigsaw and Gallery Walk are pedagogical techniques that contribute positively for the students' interaction by developing problemsolving skills as well as motivation for the opportunity to confront their ideas with the other team members, to relate concepts and to apply critical thinking. It can also be noted that the collaborative working group, applied in a significant part of the educational context, contributes profoundly to improve self-esteem, mutual assistance and responsibility, changing the typical students' passive attitude in a classroom environment.

The learner-centred approach was implemented through the constructive alignment matrix. This instrument, which defines the entire pedagogical structure, is flexible, allowing an ongoing reflection based on qualitative and quantitative results that provides a continuous improvement of objectives, learning activities and assessment. The outcomes achieved reinforce the relevance of the application of the constructive alignment matrix. Furthermore, the amendment made on the constructive alignment matrix from one academic year to another triggered a significant improvement on the outcomes produced by active learning implementation.

\section{References}

Amer, A.: Reflections on Bloom's revised taxonomy. Electron. J. Res. Educ. Psychol. 8(4), 213230 (2006)

Aronson, E., Patnoe, S.: The Jigsaw Classroom: Building Cooperation in the Classroom, 2nd edn. Addison Wesley Longman, New York (1997)

Barkley, E.F., Cross, K.P., Major, C.H.: Collaborative Learning Techniques: A Handbook for College Faculty. Jossey-Bass Publishers, San Francisco (2014)

Biggs, J.: Enhancing teaching through constructive alignment. High. Educ. 32, 1-18 (1996)

Burke, A.: Group work: how to use groups effectively. J. Effective Teach. 11(2), 87-95 (2011)

Chin, C.K., Khor, K.H., Teh, T.K.: Is gallery walk an effective teaching and learning strategy for Biology? In: Biology Education and Research in a Changing Planet, pp. 55-59. Springer, Singapore (2015). https://doi.org/10.1007/978-981-287-524-2_6

Chiriac, E.H.: Group work as an incentive for learning - students' experiences of group work. Front. Psychol. Educ. Psychol. 5 (2014). Article 558. https://doi.org/10.3389/fpsyg.2014. 00558

Duch, B.J., Groh, S.E., Allen, D.E.: The Power of Problem-Based Learning. Stylus Publishing, Virginia (2001). ISBN 1-57922-036-3

Gavrin, A.: Just-in-Time teaching. Metrop. Univ. 17(4), 9-18 (2006)

Gokhale, A.A.: Collaborative learning enhances critical thinking. J. Technol. Educ. 7(1), 22-30 (1995)

Justino, J., Rafael, S.: Teaching mathematics in tertiary education through collaborative work. In: 3rd International Conference of the Portuguese Society for Engineering Education (CISPEE 2018). IEEEXplore Digital Library (2018). https://doi.org/10.1109/cispee.2018.8593476 
Laal, M., Ghodsi, S.M.: Benefits of collaborative learning. Procedia Soc. Behav. Sci. 31, 486490 (2012). https://doi.org/10.1016/j.sbspro.2011.12.091

Livingstone, K.A.: Constructive alignment and the curriculum: a call for improved pedagogical practices in higher education. J. Bus. Manag. Soc. Sci. Res. 3(12) (2014)

OECD: Review of the tertiary education, research and innovation system in Portugal (2018). https://www.santamariasaude.pt/sgc/Assets/Plugins/CKEditor/kcfinder/Uploads/files/Review $\%$ 20of\%20TERI\%20in\%20Portugal\%206\%20February\%20DRAFT.pdf. Accessed 12 Mar 2019

Shaffer, D.W., Serlin, R.C.: What good are statistics that don't generalize? Educ. Res. 33(9), 14-25 (2004). https://doi.org/10.3102/0013189X033009014

Tashakkori, A., Teddlie, C.: Mixed Methodology: Combining Qualitative and Quantitative Approaches. SAGE Publications, Thousand Oaks (1998) 